\title{
Loneliness of the Marginalized
}

\author{
Ami Rokach \\ ${ }^{1}$ York University, Toronto, Canada \\ ${ }^{2}$ Walden University, Minneapolis, USA \\ ${ }^{3}$ The Center for Academic Studies, Or Yehuda, Israel \\ Email: arokach@yorku.ca
}

Received 12 June 2014; revised 15 July 2014; accepted 12 August 2014

Copyright @ 2014 by author and Scientific Research Publishing Inc.

This work is licensed under the Creative Commons Attribution International License (CC BY). http://creativecommons.org/licenses/by/4.0/

c) (i) Open Access

\begin{abstract}
This review article provides a bird's eye view of several population groups that are marginalized, ostracized, and stigmatized. Those include the homeless, the physically disabled, and psychiatric patients, Lesbian, Gay, Bisexual and Transgender (LGBTs), and those afflicted with Human immunodeficiency Virus (HIV) or with Acquired Immunodeficiency Syndrom (AIDS). Their condition, how it leads to social isolation and loneliness, and its effects on them, their illness or condition, and their quality of life are described. Interestingly, while all experience loneliness, each group expresses and addresses it differently. Awareness of those unique expressions of loneliness could assist mental health workers in identifying, addressing, and helping the marginalized cope with loneliness.
\end{abstract}

\section{Keywords}

\section{Loneliness, Illness, HIV, AIDS, Homeless, Psychiatric Patients, LGBT}

\section{Introduction}

Recent studies suggest that a large proportion of the population is frequently lonely (Rokach \& Sha'ked, 2013). Ornish (1998) stated at the very beginning of his book Love and Survival: “'Our survival depends on the healing power of love, intimacy, and relationships. Physically. Emotionally. Spiritually. As individuals. As communities. As a culture. Perhaps even as a species.’' (p. 1). And indeed, loneliness has been linked to depression, anxiety and interpersonal hostility (Lau \& Kong, 1999), to drug and alcohol abuse (McWhirter, 1990), to an increased vulnerability to health problems (Jones et al., 1990), and even to suicide (Tondo, Baldessarini et al., 1999). This paper will address Marginalization, which its very nature brings about a sense of disconnection, dissociation from society at large, and a sense of aloneness and loneliness (see also Kidd, 2007). 


\section{The Homeless}

Interestingly, whereas people once got most of their knowledge about the homeless from the newspapers, or from documentaries and television programs, and, of course from movies, regrettably, North Americans can now see scores of homeless on the streets, on their way to and from work (Hombs, 1994). There is generally no accepted definition of homelessness. Farrington and Robinson (1999) observed that homelessness simply means to be without a home. However, Kelling (1991) maintained that homelessness is not just rootlessness, but it is also the lack of a secure and appropriate home. Apparently, some of the homeless do have a place to stay, but most are transient and move frequently from one living quarter to another (Kramer \& Barker, 1996).

Daily survival of the homeless requires adaptation, focusing on food, clothing and personal hygiene. As the person spends more time on the street as a homeless, daily routines develop and adaption to street life progresses. The homeless are not only burdened with issues of daily survival, violence and social ostracism, but also experience loneliness, depression and fear (Sumerlin, 1995). Hagan and McCarthy (1997) observed that the homeless in order to support themselves they may try to find work, seeking money from family/friends, panhandling, prostitution, dealing drugs, and theft. It was found that homeless perception of discrimination, which was based upon negative stereotypes that the public holds, was related to feelings of worthlessness, loneliness and social alienation, and even suicidality (Kidd, 2004).

Since homelessness is such a growing problem in the North American society, and since the homeless are basically society's outcasts who are suffering but are shunned by most of us, loneliness is no doubt their loyal companion (see also Layton, 2000). Depression, anxiety and loneliness may be caused when one is unable to secure such basic needs as food, shelter, employment, and some money coupled with the isolation and alienation which the homeless frequently experience (Kidd, 2004; Lloyd-Cobb \& Dixon, 1995). Consistent with previous qualitative analyses, perceived stigma, which the homeless are so intimately familiar with, was found to have a significant relationship with low self-esteem, loneliness, suicidal ideation, and feeling trapped, which in turn gives rise to feelings of helplessness and hopelessness and may bring about has suicidality among the homeless (Kidd, 2006, 2007).

\subsection{Physical Disabilities}

People with physical disabilities may not come to mind when you think about marginalized groups. However, my research into the loneliness of these people, the sick, disfigured, and sometimes the terminally ill, may justify seeing them as a marginalized group (Rokach, 2006). The World Health Organization (WHO) (see in Kennedy, 1999) distinguished between impairment, disability and handicap. Impairment refers to the loss of function of a specific body organ or system. (i.e. muscular weakness). Disability pertains to a restriction in performing a normal activity (such as walking). A handicap is seen as the result of impairment or disability, which consequently prevents the individual from fulfilling a social role, such as an inability to work.

Depending on the organ or the bodily system which is affected, physical disabilities may cause problems related to dexterity of movement, vision or hearing and consequently a person's ability to communicate with others may be affected or diminished. No question about it, that the occurrence of disability is a jolt, a psychosocial shock. The process that leads to the marginalization of the disabled is as follows: One element that concretely makes the ill feel marginalized is what Kennedy (1999) referred to as the "disabling environment” (p. 138), that refers to (what may have recently improved to a degree) the architectural and social inaccessibility of our society, which is geared for able-bodied people, which is often interwoven with emotional distress, turmoil, and pain, and highlights the emotional and psychological distress that the disabled experience, including feelings of powerlessness, helplessness, and social isolation. It is intuitively apparent that adaptation to the physical barriers that our able-bodied culture so easily puts around is quite challenging for those with physical disabilities, and they consequently suffer stress and possibly embarrassment and social awkwardness (Rokach, 2005). Kitto (1988) further stated that "illness is something which affects the smooth working of our lives. It stops our work pattern, interferes with our relationship, allows pain or distress to invade us and stops us from pursuing our dreams” (p. 111). Such is the enormous impact that physical disability brings about. Being different from the able-bodied people, and being (usually) visibly different, result in stigmatization, marginalization and loneliness (Lupton \& Seymour, 2000).

Disability negatively influences one’s social network and it, thus, leads to loneliness (see Hawkley, Thisted, 
Masi, \& Cacioppo, 2010 for related review). Similarly, disabling health problems can make emotional closeness and intimacy more difficult since the disabled may experience a decrease in the number of activities shared with friends, lack of spontaneity and problems with sexuality. The irritability that the disabled may experience as a result of his condition, may lead (if one is married) to frustrations and anger in the well spouse, and that can result in feelings of frustrations and resentment of both partners, and thus cause them to become alienated from one another (Rokach \& Sha'ked, 2013). It was found that disability is related to higher levels of emotional loneliness. For men, the effects were cumulative, while for women, the effects of own and spousal disability slightly reinforced each other. Those effects of own and spousal disability on emotional loneliness were not reduced or altered by the frequency of the emotional and instrumental support that were offered to the spouse (Korporaal, van Groenou, \& van Tilburg, 2008).

\subsection{Psychiatric Patients}

In a recent survey in the USA, 1300 people diagnosed with mental illness were asked to describe their situation and how it felt to be a psychiatric patient. They voiced their concern that others would see them unfavourably, they mentioned mass media hurtful messages, and added that they avoided telling others that they have a psychiatric problem, and that they were advised to lower their expectations in life, only because they had a psychiatric label (Thornicroft, 2006). "In the Western culture, stereotypes of people with mental illness often suggest that they are dangerous, incompetent, unable to care for themselves, and childlike" (Ottati, Bodenhausen, \& Newman, 2005: p. 100). The general public, commonly bases its inference that one may have mental illness on four signals: psychiatric symptoms, social skills deficits, physical appearance, and labels that were attached to some people (Corrigan \& Kleinlein, 2005). However, a definition of mental illness, rests on a clinically significant behavioral pattern that leads to distress (e.g. a painful symptom), on a disability (an impairment in an important life function), or a potential loss of personal freedom (see Rokach, 2009).

Phillips (1990) has suggested that society views psychiatric patients as damaged, defective and as less socially marketable than the general population. That perception of these people as damaged goods is what affects their social status and leads to stigmatization (see also Rokach \& Sha'ked, 2013). What seems to contribute to stigmatization of people with mental illness are psychiatric labels, patients' own labelling, or by association, i.e. a patient coming out of an office in a mental hospital. Link and Phelan (2001) found that once members of the general public found out that one has mental illness, there is readiness to label and stigmatize the person even without any aberrant behaviour. It was clearly indicated that psychiatric labels were closely associated with negative societal reactions, stigmatization, and consequent alienation (see also Thornicroft, 2006).

Psychiatric patients, adopt that social stigma, and consequently devalue themselves and sometimes take on the attitudes and behaviors that society holds towards them. In their study of the results of such stigma, Ritsher and Phelan (2004) found that these patients suffered alienation and distress. Alienation, then, reduces self-esteem and may contribute to depression and loneliness.

A possible result of the process described above, is the increasing withdrawal and intense social anxiety that could follow and which may lead to loss of friends and great difficulty in creating a social support system. It was found that frequent admissions to psychiatric services were positively correlated with social isolation, which unfortunately is so vital for one's rehabilitation and coping with one's mental illness (Bradshaw \& Haddock, 1998). Erdner, Magnusson, Nystrom and Lutzen (2005) found that psychiatric patients perceive themselves as undesirable, vulnerable, and clearly part of a marginalized group. Many of them report having little hope that their lives would improve, and are very concerned about their future. Apparently, some experiences of people with mental illness are so traumatic that they may stop doing what had previously been a very important aspect of their lives, i.e. connecting with others. The hurt, distress, embarrassment, or humiliation that they have suffered when interacting with others, may completely curtail their attempts to form new relationships that could provide them the very needed support which they crave, or alternatively may cause them to not apply for work which is so fundamental for their survival in a dignified manner (Thornicroft, 2006).

\section{LGBTs (Lesbian, Gay, Bisexual, Transgender)}

Another marginalized group are those whose sexual orientation is different from that of the majority. And it seems that this group has its share of loneliness. A study found that urban gay men scored on the UCLA loneliness Scale (Russell, 1996) higher than college students, nurses, and the elderly that they looked at. These find- 
ings lend credence to their hypothesis that loneliness experienced by gay men (and most probably lesbians and bisexuals as well) is associated with not just the intimacy that may or may not exist in their personal relationships but also their perceptions of how supportive, or unsupportive, their community is (Martin \& Knox, 1997).

Martin and D'augeli (2003) have studied older gays and lesbians, who grew up during a time when their sexual orientation was not as well tolerated as it is today. Therefore, in addition to the negative events related to society's homophobia, lesbians, gay men, transsexuals, and bisexuals experienced stigmatization and discrimination as members of a sexual minority group in a dominant heterosexual society. That experience revolved around the incongruence between their culture, needs, and experiences and the greater societal structures. Grossman, D'augelli and O'connell (2002) reported that 27\% of their participants reported feeling lonely. The older LGBT apparently experienced their early identity development at time when homosexuality was synonymous with abnormality, inferiority, and shame, and so many of them feared that identifying their sexual orientation would lead to humiliation, dishonour, and rejection, so they remained silent and invisible.

Three minority stressors contributed to this group's loneliness: experiences with prejudice events, expectations of prejudice reactions, and LGBT network (Kuyper \& Fokkema, 2010). The authors stated that the positive correlation between minority stress and loneliness is commensurate with outcomes of other studies on social and health-related issues (e.g., mental health, relationship quality, sexual problems, domestic violence, HIV risk behavior, substance use, job stress, and body image concerns) Hatzenbuehler, Nolen-Hoeksema, \& Erickson, 2008; Zamboni \& Crawford, 2007). Social prohibitions against same-sex relationships cause many gay men to hide, ignore, and suppress their feelings resulting in their identity development being strongly negatively influenced in that they feel that they are being different, which in turn, exacerbates isolation and feelings of loneliness (Flowers \& Buston, 2001). The lack of social support that they experience, contribute to lower psychosocial functioning and increased loneliness. Unlike other groups that are marginalized in society and which were addressed above, a significant proportion of LGBTs do not, commonly, have family support. Many report that they feel forced to choose between living an openly gay life without the support of their families, or being so desperate to get their family's support, they may be living a "double life" by hiding their sexual orientation (Chng et al., 2003). For those who remain connected to their family but cannot be open about their sexuality, loneliness is exacerbated by the inability to express their true self or sexual identity.

\section{HIV and AIDS}

As opposed to cancer for instance, and because of the increased stigma attached to it, HIV carries with it a more significant burden of loneliness and social alienation. Public judgements about culpability, immorality, and promiscuity are commonly directed towards those afflicted with HIV or AIDS (Bletzer, 2007). As a result, People Living With HIV (PLWH) face such social consequences as ostracism and isolation (Stutterheim et al., 2012) as well as possible rejection from their social networks, workplace, schools, housing, and even members of the healthcare system (Earnshaw \& Kalichman, 2014; Whetten-Goldstein, 2013). PLWH are highly stigmatized and this stigma produces increased anxiety and depression (Miles, Isler, Banks, Sengupta, \& Corbie-Smith, 2011; Varni et al., 2012), decreased self-esteem, and intentional self-isolation in order to avoid disclosure of one's HIV status (Herek et al. 2013). HIV is very hard to conceal from others and that may lead to heightened vulnerability to stigma which is often associated with PLWH (Herek, 2014). The virus produces extreme weight loss and emaciation; while additionally PLWH may at time develop Kaposi's sarcoma, a cancer characterized by purple lesion on the skin as a result of the antiretroviral therapy (Herek, 2014; Palmer et al., 2011).

HIV, suggest some researchers, is mostly prevalent among populations that are already stigmatized because of either gender inequalities (women) (Lekas et al., 2011; Ndinda et al., 2007; Mayers et al., 2005), racism (minorities such as black people) (Dodds, 2006; Heckman, 2006), sexual orientation (homosexuals and bisexuals), or antisocial behaviour such as IV drug users and criminals (Liamputtong, 2014). Not only that PLWH experience loneliness in relation to the stigma that is held about them, but there are important effects on their general quality of life as a result of their experience with stigma-related social rejection which in turn has been shown to affect their treatment adherence and efficacy (Earnshaw \& Kalichman, 2014). Internalizing the stigma is also linked to a variety of psychosocial factors in PLWH including increased psychological distress (Mak et al., 2007), increased feelings of shame (Sayles et al. 2008), increased incidence of depression (Grov et al., 2010; Kalichman et al., 2009), poorer physical health (Sayles et al. 2008) diminished social support (Kalichman et al., 2009) and suicide attempts (Courtenay-Quirk et al., 2006). 


\section{Conclusion}

To conclude, it may be stated that stable and rewarding interpersonal relationships are, most probably, the single most important factor influencing a person's quality of life, and that is particularly so with the marginalized (see Van Tilburg \& van Groenou, 2002). The literature points out that relationships provide practical aid, emotional support, information, and assistance with decision making (Cacioppo, Hughs, Hawkley, \& Thisted, 2006). Relationships are also important as safeguards against stress and psychological illness. It has been shown that there are clear mental and physical health benefits associated with the development of interpersonal networks, and the loneliness associated with having unsatisfactory social networks (Stanfeld 1999). Yet, for many of the marginalized maintaining such supportive social network and closeness with others may be a most challenging and demanding task, though once achieved it can improve their quality and even duration of life significantly (see Duvdevany \& Arar 2004; Rokach \& Sha’ked, 2013).

\section{References}

Bletzer, K. V. (2007). Identity and Resilience among Persons with HIV: A Rural African American Experience. Qualitative Health Research, 17, 162-175.

Bradshaw, T., \& Haddock, G. (1998). Is Befriending by Trained Volunteers of Value to People Suffering from Long-Term Mental Illness? Journal of Advanced Nursing, 27, 713-720. http://dx.doi.org/10.1046/j.1365-2648.1998.00618.x

Cacioppo, J. T., Hughs, M. E., Hawkley, L. C., \& Thisted, R. A. (2006). Loneliness as a Specific Risk Factor for Depressive Symptoms: Cross Sectional and Longitudinal Analyses. Psychology and Aging, 21, 140-151. http://dx.doi.org/10.1037/0882-7974.21.1.140

Chng, C. L.,Wong, F., Park, R., Edberg, M., \& Lai, D. (2003). A Model for Understanding Sexual Health among Asian American/Pacific Islander Men Who Have Sex with Men (MSM) in the United States. AIDS Education and Prevention, 15, 21. http://dx.doi.org/10.1521/aeap.15.1.5.21.23611

Corrigan, P. W., \& Kleinlein, P. (2005). Impact of Mental Illness Stigma. In: P. W. Corrigan (Ed.), On the Stigma of Mental illness: Practical Strategies for Research and Social Change (pp. 186-199). Washington, DC: American Psychological Association. http://dx.doi.org/10.1037/10887-001

Courtenay-Quirk, C., Wolitski, R. J., Parsons, J. T., \& Gómez, C. A. (2006). Is HIV/AIDS Stigma Dividing the Gay Community? Perceptions of HIV-Positive Men Who Have Sex with Men. AIDS Education and Prevention, 18, 56-67.

http://dx.doi.org/10.1521/aeap.2006.18.1.56

Dodds, C. (2006). HIV-Related Stigma in England: Experiences of Gay Men and Heterosexual African Migrants Living with HIV. Journal of Community \& Applied Social Psychology, 16, 472-480. http://dx.doi.org/10.1002/casp.895

Duvdevany, I., \& Arar, E. (2004) Leisure Activities, Friendships and Quality of Life of Persons with Intellectual Disability: Foster Homes vs. Community Residential Settings. International Journal of Rehabilitation Research, 27, $289-296$. http://dx.doi.org/10.1097/00004356-200412000-00006

Earnshaw, V. A., \& Kalichman, S. C. (2014). Stigma Experienced by People Living with HIV/AIDS. In P. Liamuttong (Ed.), Stigma, Discrimination and Living with HIV/AIDS: A Cross-Cultural Perspective (pp. 23-38). New York, NY: Springer. http://dx.doi.org/10.1111/j.1471-6712.2005.00364.x

Erdner, A., Magnusson, A., Nystrom, M., \& Lutz'en, K. (2005). Social and Existential Alienation Experienced by People with Long-Term Mental Illness. Scandinavian Journal of Caring Science, 19, 373-380.

Farrington, A., \& Robinson, W. P. (1999). Homelessness and Strategies of Identity Maintenance: A Participant Observation Study. Journal of Community and Applied Social Psychology, 9, 175-194.

http://dx.doi.org/10.1002/(SICI)1099-1298(199905/06)9:3<175::AID-CASP497>3.0.CO;2-R

Flowers, P., \& Buston, K. (2001). “I Was Terrified of Being Different”: Exploring Gay Men’s Accounts of Growing-Up in a Heterosexist Society. Journal of Adolescence, 24, 51-65.

Grossman, A. H., D’augelli, A. R., \& O’connell, T. S. (2002). Being Lesbian, Gay, Bisexual, and 60 or Older in North America. Journal of Gay \& Lesbian Social Services, 13, 23-40. http://dx.doi.org/10.1300/J041v13n04_05

Grov, C., Golub, S. A., Parsons, J. T., Brennan, M., \& Karpiak, S. E. (2010). Loneliness and HIV-Related Stigma Explain Depression among Older HIV-Positive Adults. AIDS Care, 22, 630-639. http://dx.doi.org/10.1080/09540120903280901

Hagan, J., \& McCarthy, B. (1997). Mean Streets: Youth Crime and Homelessness. Cambridge: Cambridge University Press. http://dx.doi.org/10.1017/CBO9780511625497

Hatzenbuehler, M. L., Nolen-Hoeksema, S., \& Erickson, S. J. (2008). Minority Stress Predictors of HIV Risk Behavior, Substance Use, and Depressive Symptoms: Results from a Prospective Study of Bereaved Gay Men. Health Psychology, 27, 455-462. 
Hawkley, L. C., Thisted, R. A., Masi, C. M., \& Cacioppo, J. T. (2010). Loneliness Predicts Increased Blood Pressure: 5-Year Cross-Lagged Analyses in Middle-Aged and Older Adults. Psychology and Aging, 25, 132-141. http://dx.doi.org/10.1037/a0017805

Heckman, B. D. (2006). Psychosocial Differences between Whites and African Americans Living with HIV/AIDS in Rural Areas of 13 US States. The Journal of Rural Health, 22, 131-139. http://dx.doi.org/10.1111/j.1748-0361.2006.00021.x

Herek, G. (2014). HIV-Related Stigma. In P. W. Corrigan (Ed.), The Stigma of Disease and Disability: Understanding Causes and Overcoming Injustices (pp. 121-138). Washington DC: American Psychological Association.

Herek, G. M., Saha, S., \& Burack, J. (2013). Stigma and Psychological Distress in People with HIV/AIDS. Basic and Applied Social Psychology, 35, 41-54. http://dx.doi.org/10.1080/01973533.2012.746606

Hombs, M. E. (1994). American Homelessness. Santa Barbara, CA: Abc-Cilo.

Jones, W. H., Rose, J., \& Russell, D. (1990). Loneliness and Social Anxiety. In H. Leitenberg (Ed.), Handbook of Social and Evaluation Anxiety (pp. 247-266). New York, NY: Plenum. http://dx.doi.org/10.1007/978-1-4899-2504-6 9

Kalichman, S. C., Simbayi, L. C., Cloete, A., Mthembu, P. P., Mkhonta, R. N., \& Ginindza, T. (2009). Measuring AIDS Stigmas in People Living with HIV/AIDS: The Internalized AIDS-Related Stigma Scale. AIDS Care, 21, 87-93. http://dx.doi.org/10.1080/09540120802032627

Kelling, K. (1991). Older Homeless People in London. London: Age Concerns.

Kennedy, P. (1999). Working with Physically Disabled People. In J. Marzillier, \& J. Hall (Eds.), What Is Clinical Psychology (pp. 134-156). New York, NY: Oxford University Press.

Kidd, S. A. (2004). “The Walls Were Closing in and We Were Trapped”: A Qualitative Analysis of Street Youth Suicide. Youth and Society, 36, 30-55. http://dx.doi.org/10.1177/0044118X03261435

Kidd, S. A. (2006). Factors Precipitating Suicidality among Homeless Youth: A Quantitative Follow-Up. Youth and Society, 37, 393-422. http://dx.doi.org/10.1177/0044118X05282763

Kidd, S. A. (2007). Youth Homelessness and Social Stigma. Journal of Youth and Adolescence, 36, 291-299. http://dx.doi.org/10.1007/s10964-006-9100-3

Kitto, P. (1988). The Patient as Healer: How We Can Take Part in Our Own Recovery. In M. Kidel, \& S. Rowe-Leete, (Eds.), The Meaning of Illness (pp. 109-119). New York, NY: Routledge.

Korporaal, M., van Groenou, M. I. B., \& van Tilburg, T. G. (2008). Effects of Own and Spousal Disability on Loneliness among Older Adults. Journal of Aging and Health, 20, 306-325.

Kramer, B. J., \& Barker, J. C. (1996). Homelessness among Older American Indians, Los Angeles, 1987-1989. Human Organization, 55, 396-408.

Kuyper, L., \& Fokkema, T. (2010). Loneliness among Older Lesbian, Gay, and Bisexual Adults: The Role of Minority Stress. Archives of Sexual Behavior, 39, 1171-1180. http://dx.doi.org/10.1007/s10508-009-9513-7

Lau, S., \& Kong, C. K. (1999). The Acceptance of Lonely Others: Effects of Loneliness and Gender of the Target Person and Loneliness of the Perceiver. Journal of Social Psychology, 139, 229-241. http://dx.doi.org/10.1080/00224549909598377

Layton, J. (2000). Homelessness: The Masking and Unmasking of a Crises. Toronto: Penguin Books.

Lekas, H., Siegel, K., \& Leider, J. (2011). Felt and Enacted Stigma among HIV/HCV-Coinfected Adults: The Impact of Stigma Layering. Qualitative Health Research, 21, 1205-1219. http://dx.doi.org/10.1177/1049732311405684

Liamputtong, P. (2014). Stigma, Discrimination, and HIV/AIDS: An Introduction. In P. Liamuttong (Ed.), Stigma, Discrimination and Living with HIV/AIDS: A Cross-Cultural Perspective (pp.1-19). New York, NY: Springer.

Link, B. G., \& Phelan, J. C. (2001). Conceptualizing Stigma. Annual Review of Sociology, 27, 363-385. http://dx.doi.org/10.1146/annurev.soc.27.1.363

Lloyd-Cobb, P., \& Dixon, D. R. (1995). A Preliminary Evaluation of the Effects of a Veterans’ Hospital Domiciliary Program for the Homeless Persons. Research on Social Work Practise, 5, 309-316. http://dx.doi.org/10.1177/104973159500500304

Lupton, D., \& Seymour, W. (2000). Technology, Selfhood and Physical Disability. Social Science and Medicine, 50, 18511862.

Mak, W. W. S., Cheung, R. Y. M., Law, R. W., Woo, J., Li, P. C. K., \& Chung, R. W. Y. (2007). Examining Attribution Model of Self-Stigma on Social Support and Psychological Well-Being among People with HIV+/AIDS. Social Science \& Medicine, 64, 1549-1559.

Martin, J. I., \& D’augelli, A. R. (2003). How Lonely Are Gay and Lesbian Youth? Psychological Reports, 93, 486. http://dx.doi.org/10.2466/pr0.2003.93.2.486

Martin, J. I., \& Knox, J. (1997). Loneliness and Sexual Risk Behaviour in Gay Men. Psychological Reports, 81, 815-825. 
http://dx.doi.org/10.2466/pr0.1997.81.3.815

Mayers, A. M., Naples, N. A., \& Nilsen, R. D. (2005). Existential Issues and Coping: A Qualitative Study of Low-Income Women with HIV. Psychology \& Health, 20, 93-113. http://dx.doi.org/10.1080/08870440410001722949

McWhirter, B. T. (1990). Loneliness: A Review of Current Literature, with Implications for Counselling and Research. Journal of Counselling and Development, 68, 417-423. http://dx.doi.org/10.1002/j.1556-6676.1990.tb02521.x

Miles, M. S., Isler, M. R., Banks, B. B., Sengupta, S., \& Corbie-Smith, G. (2011). Silent Endurance and Profound Loneliness: Socioemotional Suffering in African Americans Living with HIV in the Rural South. Qualitative Health Research, 21, 489-501. http://dx.doi.org/10.1177/1049732310387935

Ndinda, C., Uzodike, U. O., Chimbwete, C., \& Pool, R. (2007). Gender Relations in the Context of HIV/AIDS in Rural South Africa. AIDS Care, 19, 844-849. http://dx.doi.org/10.1080/09540120701203923

Ornish, D. (1998). Love \& Survival: The Scientific Basis for the Healing Power of Intimacy. New York, NY: Harper Collins.

Ottati, V., Bodenhausen, G. V., \& Newman, L. S. (2005). Social Psychological Models of Mental Illness Stigma. In P. W. Corrigan (Ed.), On the Stigma of Mental Illness: Practical Strategies for Research and Social Change. Washington DC: American Psychological Association.

Palmer, A. K., Duncan, K. C., Ayalew, B., Zhang, W., Tzemis, D., Lima, V., Montaner, J., \& Hogg, R. S. (2011). “The Way I See It": The Effect of Stigma and Depression on Self-Perceived Body Image among HIV-Positive Individuals on Treatment in British Columbia, Canada. AIDS Care, 23, 1456-1466. http://dx.doi.org/10.1080/09540121.2011.565021

Phillips, M. J. (1990). Damaged Goods: Oral Narratives of Disability on American Culture. Social Science \& Medicine, 30, 849-957.

Ritsher, J. B., \& Phelan, J. C. (2004). Internalized Stigma Predicts Erosion of Morale among Psychiatric Outpatients. Psychiatry Research, 129, 257-265. http://dx.doi.org/10.1016/j.psychres.2004.08.003

Rokach, A. \& Sha'ked, A. (2013). Together and Lonely: Loneliness in Intimate Relationships-Causes and Coping. New York, NY: Nova Publishers.

Rokach, A. (2005). Homeless Youth: Coping with Loneliness. International Journal of Adolescence and Youth, 12, 91-105. http://dx.doi.org/10.1080/02673843.2005.9747945

Rokach, A. (2009). How Do People with Psychological Disorders Cope with Loneliness. Psychology Journal, 6, $197-212$.

Rokach, A., Lechier-Kimel, R., \& Safarov, A. (2006). Loneliness of People with Physical Disabilities. Social Behavior and Personality: An International Journal, 34, 681-699. http://dx.doi.org/10.1207/s15327752jpa6601_2

Russell, D. (1996). UCLA Loneliness Scale (Version 3): Reliability, Validity, and Factor Structure. Journal of Personality Assessment, 66, 20-40. http://dx.doi.org/10.1207/s15327752jpa6601 2

Stanfeld, S. (1999). Social Support and Social Cohesion. In M. Marmot, \& R. Wilkinson (Eds.), Social Determinants of Health (pp. 155-178). Oxford: Oxford University Press.

Stutterheim, S. E., Bos, A. E. R., Shiripinda, I., de Bruin, M., Pryor, J. B., \& Schaalma, H. P. (2012). HIV-Related Stigma in African and Afro-Caribbean Communities in the Netherlands: Manifestations, Consequences and Coping. Psychology \& Health, 27, 395-411. http://dx.doi.org/10.1080/08870446.2011.585426

Sumerlin, J. R. (1995). Adaptation to Homelessness: Self-Actualization, Loneliness, and Depression in Street Homeless Men. Psychological Reports, 77, 295-314. http://dx.doi.org/10.2466/pr0.1995.77.1.295

Thornicroft, G. (2006). Shunned: Discrimination against People with Mental Illness. Oxford: Oxford University Press.

Tondo, L., Baldessarini, R. J., Hennen, J., Minnai, G. P., Salis, P., Scamonatti, L., Masia, M., Ghiani, C., \& Mannu, P. (1999). Suicide Attempts in Major Affective Disorder Patients with Comorbid Substance Use Disorders. Journal of Clinical Psychiatry, 60, 113-116. http://www.ncbi.nlm.nih.gov/pubmed/10073390

Van Tilburg, T. G., \& van Groenou, M. I. B. (2002). Network and Health Changes among Older Dutch Adults. Journal of Social Issues, 58, 697-713. http://dx.doi.org/10.1111/1540-4560.00041

Varni, S. E., Miller, C. T., McCuin, T., \& Solomon, S. (2012). Disengagement and Engagement Coping with HIV/AIDS Stigma and Psychological Well-Being of People with HIV/AIDS. Journal of Social and Clinical Psychology, 31, $123-150$. http://dx.doi.org/10.1521/jscp.2012.31.2.123

Whetten-Goldstein, K. (2013). You're the First One I've Told: The Faces of HIV in the Deep South (2nd ed.). Piscataway, NJ: Rutgers University Press.

Zamboni, B. D., \& Crawford, I. (2007). Minority Stress and Sexual Problems among African-American Gay and Bisexual Men. Archives of Sexual Behavior, 36, 569-578. http://dx.doi.org/10.1007/s10508-006-9081-z 
Scientific Research Publishing (SCIRP) is one of the largest Open Access journal publishers. It is currently publishing more than 200 open access, online, peer-reviewed journals covering a wide range of academic disciplines. SCIRP serves the worldwide academic communities and contributes to the progress and application of science with its publication.

Other selected journals from SCIRP are listed as below. Submit your manuscript to us via either submit@scirp.org or Online Submission Portal.
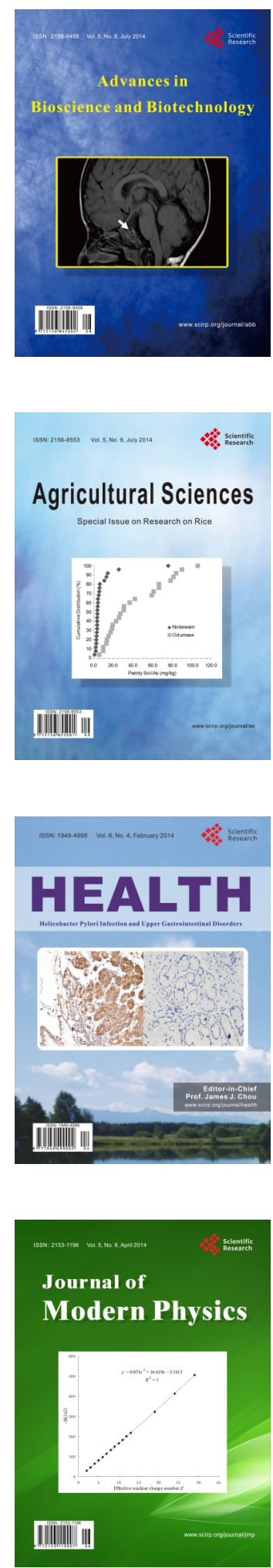
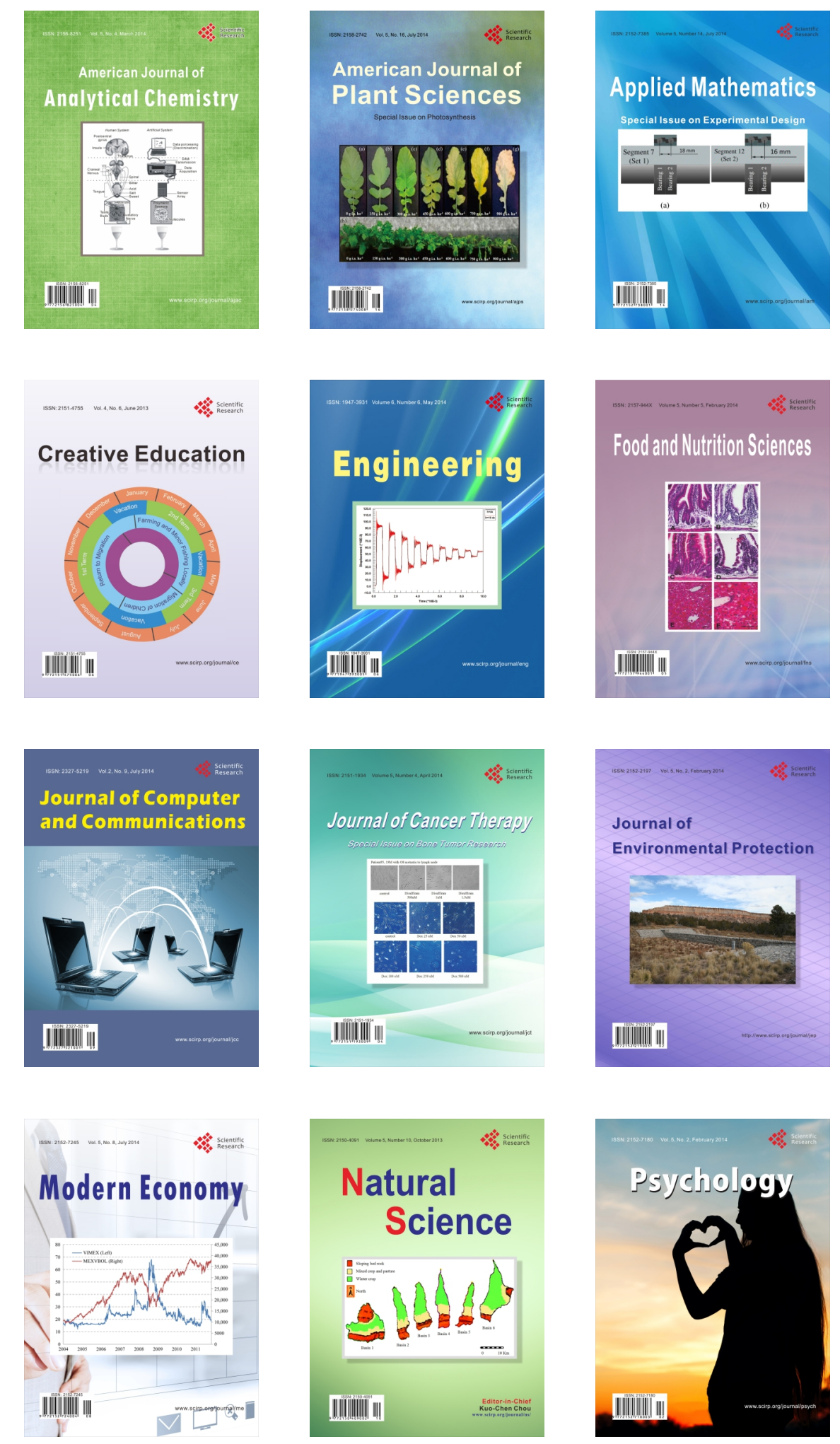